\title{
Hemorrhagic infarction at 33 days after birth in a healthy full-term neonate
}

\author{
This article was published in the following Dove Press journal: \\ Vascular Health and Risk Management \\ 7 November 2011 \\ Number of times this article has been viewed
}

\author{
Yoshitaka Kubo' \\ Kuniaki Ogasawara' \\ Akira Kurose ${ }^{2}$ \\ Hiroshi Kashimura' \\ Takahiro Koji' \\ Yasunari Otawara' \\ Jun Kamei ${ }^{3}$ \\ Manami Akasaka ${ }^{3}$ \\ Makoto Sasaki ${ }^{4}$ \\ Akira Ogawa' \\ 'Department of Neurosurgery, \\ ${ }^{2}$ Department of Pathology, \\ ${ }^{3}$ Department of Pediatrics, \\ ${ }^{4}$ Department of Radiology, Iwate \\ Medical University, Morioka, Japan
}

Correspondence: Yoshitaka Kubo

Department of Neurosurgery, Iwate

Medical University, 19-I Uchimaru,

Morioka 020-8505, Japan

$\mathrm{Tel}+8 \mathrm{I} 1965 \mathrm{I} 5 \mathrm{III}$

Fax+8I196258799

Email yokubo@iwate-med.ac.jp
Abstract: Intraparenchymal hemorrhage in the full-term neonate rarely occurs more than 2 weeks after birth, and its definitive cause remains unclear. In the present report, a case of a patient with intraparenchymal hemorrhage occurring 33 days after birth is described. Histological examination of the brain tissue obtained during hematoma evacuation through craniotomy showed hemorrhagic infarction. Patent foramen ovale may have been present and this may have led to spontaneous paradoxical cerebral embolism followed by hemorrhagic infarction.

Keywords: full-term neonate, hemorrhagic cerebral infarction, patent foramen ovale, surgery

\section{Introduction}

Intraparenchymal hemorrhage in the full-term neonate (IPH-FTN), defined as that occurring at $<3$ months of age, is more uncommon than intraventricular or subarachnoid hemorrhage associated with prematurity. ${ }^{1-3}$ Further, the majority of cases of IPH-FTN develop within 3 days of birth and are related to birth trauma. ${ }^{4-7}$ IPH-FTN rarely occurs more than 2 weeks after birth ${ }^{8}$ and its definitive cause remains unclear. In the present report, a case of a patient with IPH-FTN occurring 33 days after birth is described. Histological examination of the brain tissue obtained during hematoma evacuation through craniotomy showed hemorrhagic infarction.

\section{Case report}

A 2930 g female infant was delivered vaginally after 39 weeks gestation. Delivery occurred via a vertex presentation and was assisted by a vacuum. Apgar scores were 9 and 10 at 1 and 5 minutes, respectively. No abnormal swelling was observed in the scalp at birth. The infant was healthy until 33 days after birth, when she suddenly developed dyspnea and swallowing disturbance while nursing. Six hours later, onset of seizures was noted, beginning with clonic movements in the right upper extremity and then spreading to the right lower extremity.

The infant was admitted to the authors' hospital. On physical examination, she was comatose and had a tense fontanel. The head circumference was normal, and transillumination findings were negative. There was no evidence of external head trauma or suture diastasis. Laboratory testing showed only anemia. Routine coagulation studies were normal (prothrombin time, 12.2 seconds; activated partial thromboplastin time, 33.4 seconds; fibrinogen, $233.4 \mathrm{mg} / \mathrm{dL}$; Thrombotest, 96.8\%) and factors predisposing to the development of venous thrombosis, such as significant dehydration, polycythemia, sepsis, and hemoglobinopathy, were absent. Chest X-ray and electrocardiogram showed 
no abnormal findings. Transthoracic echocardiogram was not performed. Head computed tomography (CT) scans showed a high-density area at the left temporo-parietal lobe with surrounding edema (Figure 1).

After admission to hospital, the patient's consciousness gradually normalized, and her eyes spontaneously opened. However, 72 hours later, the patient's consciousness suddenly decreased. CT scan demonstrated an increase in hematoma volume and low-density areas in the middle and posterior cerebral artery territories (Figure 2). Magnetic resonance imaging and angiography did not show any tumor or vascular anomaly. Digital subtraction angiography using arterial catheterization revealed no vascular lesions, including cerebral aneurysms, arteriovenous malformations, medullary venous malformations, or arterial occlusions.

The patient underwent urgent craniotomy. The hematoma was easily aspirated and no lesions (eg, vascular anomalies or tumors) were observed intraoperatively. Edematous brain tissue (volume, $1 \mathrm{cc}$ ) was removed from the parietal lobe cortex for histopathological examination. The patient experienced an uneventful postoperative course and was discharged without any apparent neurological deficits 22 days after surgery.

Histological examination of the removed brain tissue showed hemorrhagic infarction (Figure 3).

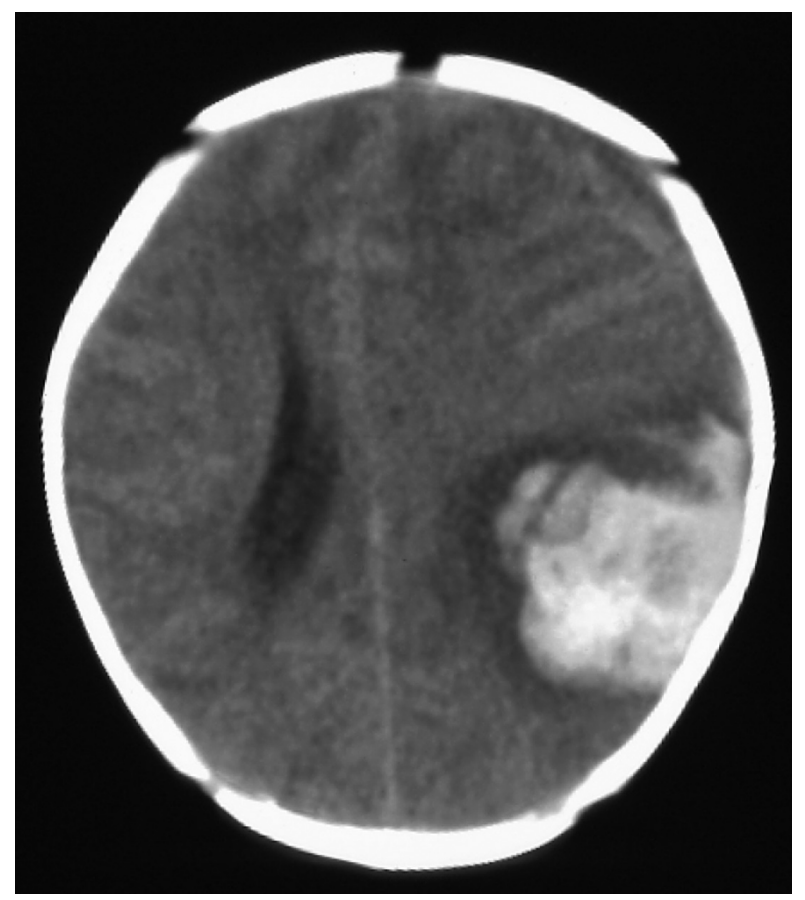

Figure I Plain computed tomography scans on admission showed a high-density area at the left temporo-parietal lobe with surrounding edema.
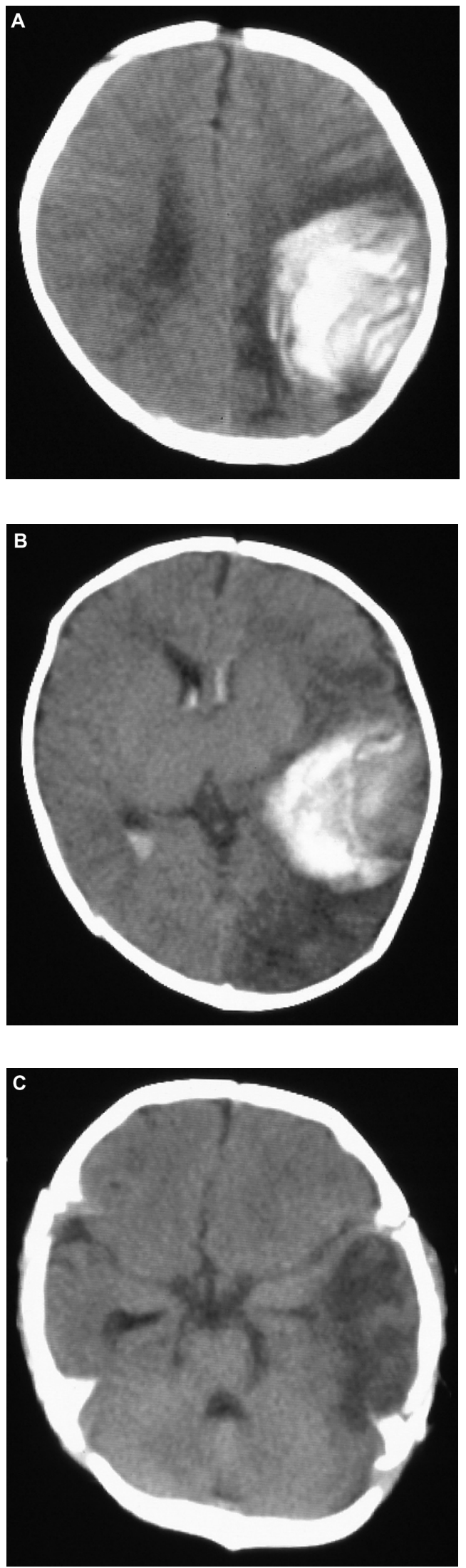

Figure 2 Plain computed tomography scan at 18 hours after admission showed increase in hematoma volume (A) and development of low-density areas in posterior (B) and middle cerebral artery (C) territories. 


\section{Discussion}

While several investigators have suggested that IPH-FTN may be ascribed to cortical contusion, venous compression/ occlusion, asphyxia related to birth trauma, ${ }^{1,3,5,7,9}$ or arterial occlusion with hemorrhagic infarction, ${ }^{8,10}$ the definitive cause of the phenomenon remains unclear.

All reported cases of IPH-FTN related to birth trauma have occurred within 3 days from birth. ${ }^{3,5,7}$ In addition, scalp swelling has been frequently observed in such patients. ${ }^{7}$ Thus, the present case was not consistent with birth trauma as the cause of hematoma.

A review of the literature identified three cases of IPH-FTN with onset between 7 and 30 days after birth. ${ }^{3,8}$ Etiology of IPH-FTN in two out of the three patients was unknown, ${ }^{3,8}$ while hemorrhage in the remaining patient was probably related to hemorrhagic infarction. ${ }^{8}$ In the case discussed here, histological examination of the resected brain tissue showed hemorrhagic infarction. Further, the increase in hematoma at 72 hours after the first hemorrhage, combined with infarction in the middle and posterior cerebral artery territories, is compatible with hemorrhagic infarction.

The incidence of patent foramen ovale in healthy term newborn infants is $54.5 \%$ between 2 and 6 months of age. ${ }^{11}$ Venous thrombosis may pass into the systemic circulation through the patent foramen ovale. ${ }^{12,13}$ In particular, Valsalva maneuvers, breath holding, crying, and straining during defecation may induce elevations in right atrial pressure and create a right-to-left shunt through the patent foramen ovale. ${ }^{14,15}$ Spontaneous paradoxical cerebral embolism associated with patent foramen ovale has rarely been reported in newborn infants. ${ }^{16}$ Echocardiography, including color-flow

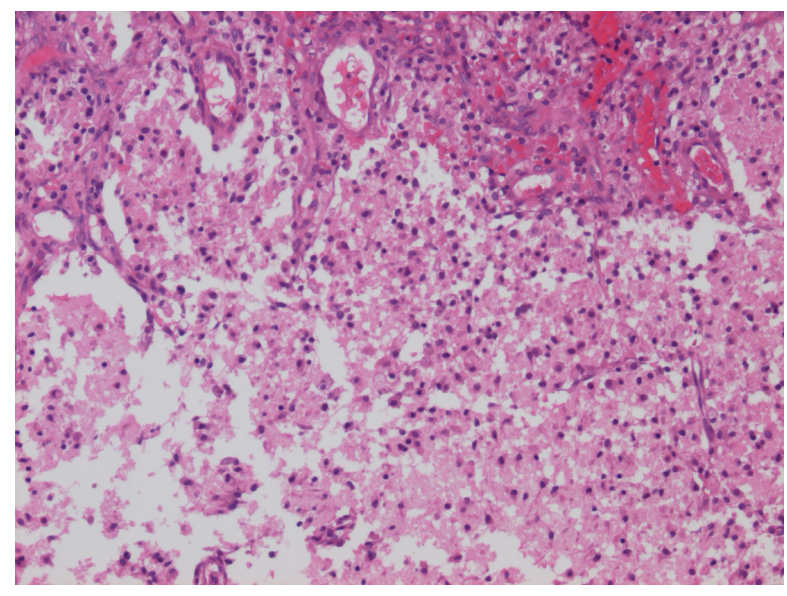

Figure 3 Middle-power view. Parenchymal loss and loosely remaining damaged brain tissue in an infarcted area. Numerous macrophages with slight to moderate lipidization appear in the damaged areas, especially around the capillaries, which show endothelial proliferation. Secondary hemorrhage is evident around the capillaries.
Doppler by an experienced pediatric-trained sonographer, is the best method to diagnose patent foramen ovale in infants. ${ }^{11,17}$ Although in the present case the patient did not undergo this examination, patent foramen ovale may have been present and may have led to spontaneous paradoxical cerebral embolism followed by hemorrhagic infarction. Echocardiography is a powerful noninvasive cardiovascular diagnostic tool and should be performed for healthy full-term neonates with intraparenchymal hemorrhage.

In conclusion, the present case suggests that intraparenchymal hemorrhage caused by hemorrhagic infarction may develop in full-term neonates.

\section{Acknowledgment}

This work was partly supported by a Grant-in-Aid for the Strategic Medical Science Research Center from the Ministry of Education, Culture, Sports, Science and Technology, Japan.

\section{Disclosure}

The authors report no conflicts of interest in relation to this work.

\section{References}

1. Cartwright GW, Culbertson K, Schreiner RL, Garg BP. Changes in clinical presentation of term infants with intracranial hemorrhage. Dev Med Child Neurol. 1979;21(6):730-737.

2. Leblanc R, O'Gorman AM. Neonatal intracranial hemorrhage. A clinical and serial computerized tomographic study. J Neurosurg. 1980;53(5): 642-651.

3. Fenichel GM, Webster DL, Wong WK. Intracranial hemorrhage in the term newborn. Arch Neurol. 1984;41(1):30-34.

4. Chaplin ER Jr, Goldstein GW, Norman D. Neonatal seizures, intracerebral hematoma, and subarachnoid hemorrhage in full-term infants. Pediatrics. 1979;63(5):812-815.

5. Hayashi T, Harada K, Honda E, Utsunomiya H, Hashimoto T. Rare neonatal intracerebral hemorrhage. Two cases in full-term infants. Childs Nerv Syst. 1987;3(3):161-164.

6. Hanigan WC, Powell FC, Palagallo G, Miller TC. Lobar hemorrhages in full-term neonates. Childs Nerv Syst. 1995;11(5):276-280.

7. Huang AH, Robertson RL. Spontaneous superficial parenchymal and leptomeningeal hemorrhage in term neonates. AJNR Am J Neuroradiol. 2004;25(3):469-475.

8. Sandberg DI, Lamberti-Pasculli M, Drake JM, Humphreys RP, Rutka JT. Spontaneous intraparenchymal hemorrhage in full-term neonates. Neurosurgery. 2001;48(5):1042-1048.

9. Hanigan WC, Powell FC, Miller TC, Wright RM. Symptomatic intracranial hemorrhage in full-term infants. Childs Nerv Syst. 1995; 11(12):698-707.

10. Bergman I, Bauer RE, Barmada MA, et al. Intracerebral hemorrhage in the full-term neonatal infant. Pediatrics. 1985;75(3): 488-496.

11. Connuck D, Sun JP, Super DM, et al. Incidence of patent ductus arteriosus and patent foramen ovale in normal infants. Am J Cardiol. 2002;89(2):244-247.

12. Mas JL, Arquizan C, Lamy C, et al. Recurrent cerebrovascular events associated with patent foramen ovale, atrial septal aneurysm, or both. N Engl J Med. 2001;345(24):1740-1746. 
13. Lamy C, Giannesini C, Zuber M, et al. Clinical and imaging findings in cryptogenic stroke patients with and without patent foramen ovale: the PFO-ASA Study. Atrial Septal Aneurysm. Stroke. 2002;33(3): 706-711.

14. Wu LA, Malouf JF, Dearani JA, et al. Patent foramen ovale in cryptogenic stroke: current understanding and management options. Arch Intern Med. 2004;164(9):950-956.
15. Cheng TO. The proper conduct of Valsalva maneuver in the detection of patent foramen ovale. J Am Coll Cardiol. 2005;45(7):1145-1146.

16. Filippi L, Palermo L, Pezzati M, et al. Paradoxical embolism in a preterm infant. Dev Med Child Neurol. 2004;46(10):713-716.

17. Ciccone MM, Scicchitano P, Zito A, et al. Different functional cardiac characteristics observed in term/preterm neonates by echocardiography and tissue doppler imaging. Early Hum Dev. 2011;87(8):555-558.

\section{Publish your work in this journal}

Vascular Health and Risk Management is an international, peerreviewed journal of therapeutics and risk management, focusing on concise rapid reporting of clinical studies on the processes involved in the maintenance of vascular health; the monitoring, prevention and treatment of vascular disease and its sequelae; and the involvement of metabolic disorders, particularly diabetes. This journal is indexed on PubMed Central and MedLine. The manuscript management system is completely online and includes a very quick and fair peer-review system, which is all easy to use. Visit http://www.dovepress.com/ testimonials.php to read real quotes from published authors.

Submit your manuscript here: http://www.dovepress.com/vascular-health-and-risk-management-journal 